\title{
TRICHLORETHYLENE ANAESTHESIA FOR EXPERIMENTAL SURGERY WITH CATS*
}

\author{
F. R. C. JohnSTONE, M.B., M.SC., F.R.G.s. (ED.), F.A.C.s., $†$ \\ H. H. Macartney, M.B., F.R.C.P. (C), 市 AND G. W. JACKson $\oint$
}

THE PROBLEMS associated with anaesthesia in small animals often do not appear until extensive surgical procedures are carried out and mortality occurs. Even then the mortality is likely to be attributed to the surgery rather than the anaesthetic, and the suitability, of the species of animal used for the experiments planned may be questioned. Modern anaesthetic techniques and agents are sometimes dismissed because they may require the services of an anaesthetist, often not available in the experimental laboratory, and too often techniques are applied blindly without regard to the possibility of species difference. Barbiturates are used as the sole anaesthetic agent because of the ease of administration, but such techniques would result in a high morbidity and mortality if they were applied in man.

Surprisingly little appears in the literature with regard to anaesthesia for experimental animals, and as a result unnecessary mortality occurs as techniques are evolved by trial and error.

Although this is not a critical study of anaesthetic agents, this paper describes the simple technique employed using trichlorethylene as the agent in fairly standard, though often quite extensive, gastric physiological experiments with cats. It contrasts this technique with those used previously, which had a much higher mortality, probably resulting from the hypoventilation and cardiovascular depression which often occurred.

In this series an anaesthetic death is considered to be one which occurred during the operation (and was not associated with gross surgical traumä) or in which the animal failed to recover consciousness before death.

Cats were used exclusively, and were generally obtained by purchase from agents, though a few were colony-bred. An attempt was made to keep the, animals in quarantine, usually for two weeks, and during this period they received distemper and pneumonitis vaccines. The operations carried out were usually the construction of gastric pouches and their modification by other subsequent procedures, including transthoracic vagotomy. Many animals were operated on more than once, some as many as four times. Because it was necessary to use diathermy a non-explosive technique was essential. The agents used were trichlorethylene (Trilene ${ }^{\circledR}$ ), halothane (Fluothane ${ }^{\circledR}$ ), pentobarbital (Nembutal ${ }^{\circledR}$ ), and thiopentone (Pentothal ${ }^{\circledR}$ ). A small experience with ether as the agent is also included.

\footnotetext{
"From the Department of Surgery, University of British Golumbia, Vancouver 8, British Columbia. This work was supported by Grant MA 793 of the Medical Research Council of Canada.

†Associate Profèssor (Surgery).

†Clinical Assistant.Professor (Anaesthesiology).

\$edical Student.
} 


\section{Metroods}

\section{Trichlorethylene-Oxygen}

\section{Preoperative Medication}

Thirty minutes prior to induction of general anaesthesia atropine gr. 1/300 was administered subcutaneously. No attempt was made to produce pre-anaesthetic sedation. Opiates in particular were avoided, to reduce emesis, excitement, and respiratory depression. Although tranquillizers are frequently used in animal work the experience in this laboratory with acepromazine (Atravet ${ }^{\circledR}$ ) was disappointing because of the delayed postoperative recovery. Succinylcholine (Anectine ${ }^{(3)}$. was given intramuscularly $(0.6 \mathrm{mg} . / \mathrm{kg}$.). This produced complete muscular paralysis within one to two minutes and enabled the cat to be placed on its back, the glottis visualized with a straight-bladed laryngoscope, and a No. 18 endotracheal tube to be passed easily and rapidly into the trathea. The tube was attached to an automatic ventilator to deliver 100 per cent oxygen. The rate and volume of the respirator having been set, the trichlorethylene vaporizer was turned on, and induction smoothly obtained with minimal struggling and scratching. The effect of the succinylcholine wears off in five to ten minutes, and further relaxant was never required as abdominal relaxation is not a problem in the cat. This'routine was repeated on several occasions in the same cats. They very, rarely showed pre-induction excitability, and this suggested that the previous administration had left no fears, an important point in the humane handling of the animals.

\section{Anaesthetic Technique}

The automatic ventilator used was the A.V.R.* (Fig. 1) unit (anaesthetizervaporizer-resuscitator). This automatically maintains a constant rate and volume of ventilation. It is powered by compressed gas. By means of a draw-over vaporizer the concentration of anaesthetic vapour may be raised. If desired, either 100 per cent oxygen or oxygen-air may be used. Ventilation can be accomplished by intermittent positive-pressure or continuous insufflation. The positive-pressure range is from 13 to $22 \mathrm{~mm}$. $\mathrm{Hg}$, and allows open-chest surgery to be undertaken. A setting range of 1-2 on the vaporizer scale was found satisfactory for maintenance when using trichlorethylene.

Just before the end of the procedure, the anaesthetic was discontinued, and 100 per cent oxygen given. The ventilation rate was slowed so that the animal might accumulate carbon dioxide and resume spontaneous respiration, which usually occurred very rapidly, the animal soon becoming conscious. When normal ventilation was thought to be adequate, the endotracheal tube was removed. On many occasions the animal would get to its feet shortly afterwards, even after extensive procedures. In most cases an intravenous drip was started after anaesthesia was induced, a No. 21 needle being placed in the femoral vein. This provided fluid replacement and a simple route for the administration of drugs intravenously.

By using the small animal mask the endotracheal tube can be dispensed with,

* N.C.G. Resuscitation and Anaesthesia Apparatus, National Cylinder Gas Co., Chicago, Ill., U.S A. 


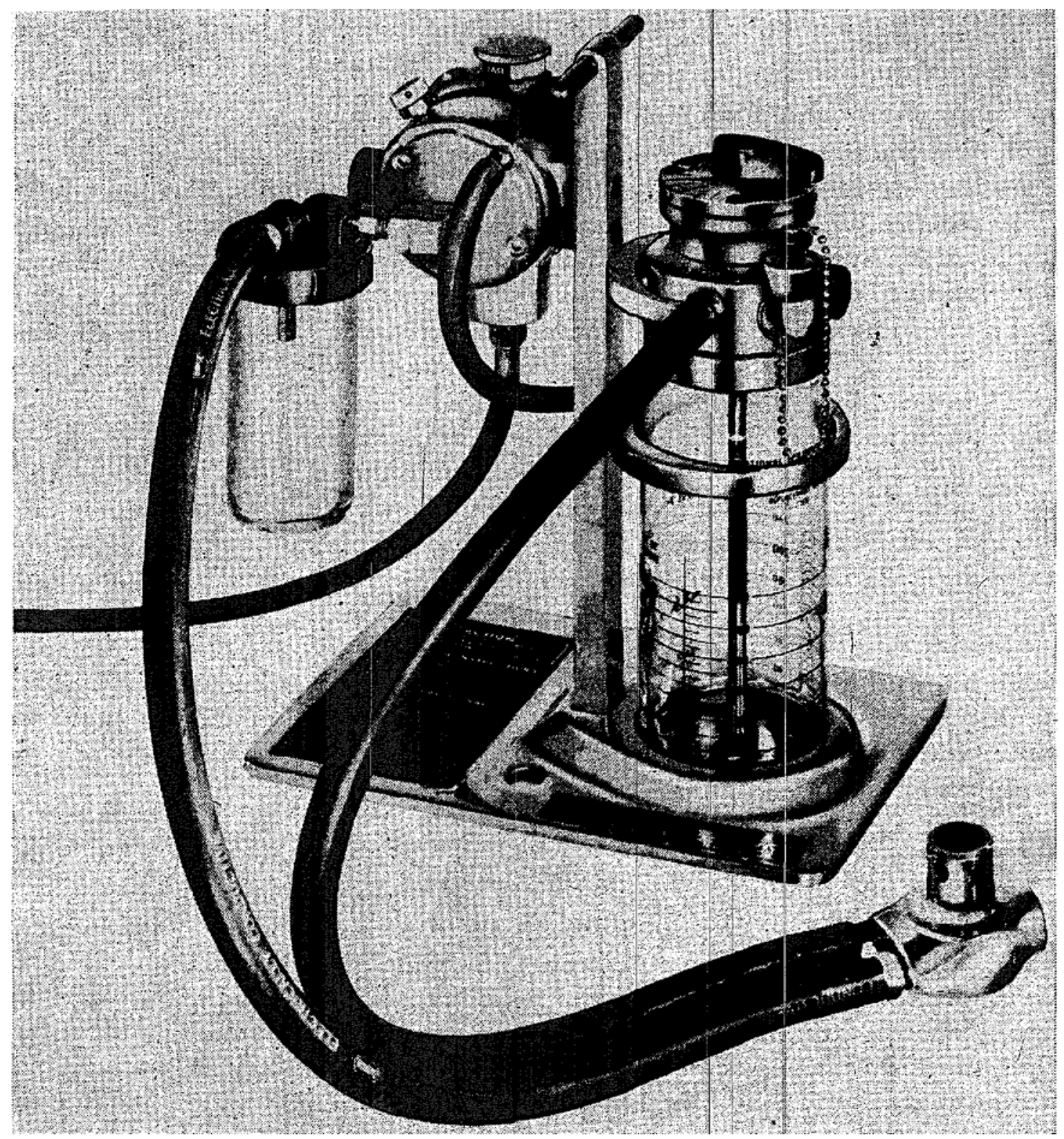

Frgure 1. Automatic ventilator for small animals.

but this does not give satisfactory control of respiration, and in all the cases reported here, an endotracheal tube was used.

\section{Halothane and Halothane-Oxygen}

Initially halothane was given by an open-drop method. While induction was rapid, struggling was a problem. It was also found difficult to control the drug accurately enough with the inexpensive equipment used, and subsequently the method employed was identical with that for trichlorethylene. A slight inerease in the concentration could produce sudden cardiovascular depression and death. Constant attention was always necessary Recovery was often delayed, with shivering and muscular rigidity. Although these difficulties might be overcome 
with a special halothane vaporizer, the cost of the drug ( $\$ 25.00$ for $125 \mathrm{ml}$.) . made its use virtually prohibitive.

\section{Ether:}

Experience with ether was limited because of its explosive qualities, which make it dangerous to use it in experimental laboratories where unshielded equipment is common. However, four animals were so anaesthetized, of which two developed bronchopneumonia postoperatively. Induction was not easy, though recovery was rapid.

\section{Barbiturates}

Pentobarbital was given by intraperitoneal injection (dose $27 \mathrm{mg} . / \mathrm{kg}$. body weight). It took about thirty minutes or more to produce surgical anaesthesia. It was difficult to regulate the dose, and in prolonged procedures additional pentobarbital was required, particularly where there was much handling of the viscera. Traction on the mesentery when anaesthesia was light was followed by heaving attempts at vomiting and evisceration of the intestines. If further doses were required they were usually given into the inferior vena cava. Results were not predictable and if an overdose was given the effects were not reversible, whereas too small a dose ${ }^{8}$ resulted in unsatisfactory conditions. Postoperative depression was common, and if prolonged, mortality was high.

In five cats after initial indüction with pentobarbital to enable an intravenous drip to be set up, anaesthesia was continued with sodium thiopentone to provide more accurate dosage with a short-acting barbiturate. This also proved difficult to regulate.

\section{Results and Discussion}

The results are shown in Table $I$. It is apparent that trichlorethylene anaesthesia provided the lowest mortality. Because of the high mortality with the thiopentone-pentobarbital combination, only five cats were so anaesthetized. This may be inadequate to evaluate the method properly.

TABLE I

\begin{tabular}{lcr}
\hline \multicolumn{1}{c}{ Agent } & $\begin{array}{c}\text { Number of } \\
\text { anaesthetics }\end{array}$ & Deaths \\
\hline Pentobarbital & 40 & 11 \\
Pentobarbital-thiopentone & 5 & 3 \\
Halothane-oxygen & 81 & 11 \\
Trichlorethylene-oxygen & 88 & 1 \\
\hline
\end{tabular}

Poor anaesthesia with barbiturates is not surprising. These drugs are hypnotics rather than anaesthetic agents, and are more suitable for prolonged sedation or minor procedures. Ideally administration should be intravenous. Intramuscular and intraperitoneal routes provide slow absorption, and the results are not always predictable. Because of this, overdosage is not uncommon. Respiratory and cardiovascular depression is produced, which probably accounts for the high 
mortality, particularly in extensive procedures. Ether is an unsuitable agent to have in experimental operating rooms because of the fire hazard. This also makes it impossible to use cyclopropane. Ether is also associated with a very high incidence of bronchopneumonia in cats, owing, likely, to its irritative action on respiratory mucosa. Halothane and trichlorethylene are both non-explosive, and non-irritant, and have rapid induction and recovery periods. Halothane has two major disadvantages. Its narrow margin of safety prevents its use with the simple apparatus described, and it also requires continuous observation, which usually means an additional attendant. The other disadvantage is, however, its cost. Trichlorethylene, on the hand, has a wide margin of safety, and its cost is small

Where gastric secretion experiments are carried out, pentobarbital probably exerts a direct inhibitory effect on histamine-provoked secretion. The effect of trichlorethylene in this regard is unknown but is being investigated.

\section{SUMMARY}

Trichlorethylene (Trilene ${ }^{\circledR}$ ) proved to be the most satisfactory agent for anaesthesia in experimental surgery with cats. It is non-explosive and provides rapid induction and recovery, good levels of anaesthesia, a wide margin of safety, low mortality, and a low post-operative complication rate. It is cheap; and can be administered with simple equipment. The technique is described. Halothane was unsuitable because of its high cost, and low margin of safety without a special vaporizer. Pentobarbital was unsatisfactory because of a high mortality and inadequate anaesthesia for the extensive experimental surgery performed in these animals.

\section{RÉSUMÉ}

En chirurgie expérimentale, chez le chat, le trichloréthylène (trilène ${ }^{\circledR}$ ) s'est avéré un agent anesthésique des plus satisfaisants. Il n'est pas explosif, il permet une induction et un réveil rapides, et il peut procurer des niveaux d’anesthésie assez profonds; il offre une grande marge de sécurité; son taux de complications postopératoires et son taux de mortalité sont bas. Il est peu coûteux et on peut l'administrer avec un appareillage simple. Nous décrivons la technique d'administration. Le fluothane ne se prête pas à cet usage à cause de son coût élevé, de sa faible marge de sécurité et de l'exigence d'un vaporisateur spécial. L'e pentobarbital ne nous a pas donné satisfaction à cause de son taux élevé de mortalité et de l'impossibilité de produire une anesthésie satisfaisante pour la chirurgie expérimentale extensive pratiquée sur ces animaux. 